\title{
THE PRIMARY HEALTH CARE PROJECT IN BELGIUM: A SURVEY ON THE UTILIZATION OF HEALTH SERVICES*
}

\author{
MarleEn Foets $^{1} \dagger$, Frans Berghmans ${ }^{2}$ and Lieve Janssens ${ }^{3}$ \\ 'Department of Health Care Administration, Erasmus University, Rotterdam, The Netherlands, \\ ${ }^{2}$ Marketing Division, Stella Artois, Leuven and ${ }^{3}$ Centre for Social Welfare, Dendermonde, Belgium
}

\begin{abstract}
The article consists of two major parts. In the Introduction a general overview is given of the Primary Health Care Project, carried out in Belgium from 1975 to 1978 in the broader framework of a large National Project in the Social Sciences. An explanation is given of the scope of the study, its method and sampling. Since the very broad study design, it was decided to make a selection of interesting results. An overview is given of the most relevant data with respect to the utilization of health care services and of medicines. After a short clarification of the concept of utilization behaviour, some data are presented in order to describe the use of medical services and the consumption of medicines. Secondly an attempt is made to explain utilization behaviour. For the explanatory model used in this project, the WHO-model functioned as an important source of inspiration. In this way it surmounted the limitations of much previous research. This model included variables on the level of the individual-perceived morbidity, predisposing factors and enabling factors - as well as system variables-such as degree of urbanization, proximity and the way of functioning of the medical supply. The research results have successfully shown that:

there is a strong relationship between perceived presence and perceived seriousness of morbidity on the one hand, utilization behaviour on the other hand;

the health perspective (including medical knowledge, values and attitudes) seems to have a differential influence on utilization behaviour, depending on age and social background of the respondent;

the inclusion of socio-structural variables is an innovation in the Belgian health care research. The hypothetical character of the relationships found here is largely supported by the research simultaneously conducted in the French-speaking region of Belgium;

accessibility and socialization are factors having a clear influence on the use of general practice services. The importance of the presence and the organization of the supply in the explanation of utilization behaviour is partly confirmed.
\end{abstract}

\section{INTRODUCTION}

\section{Scope of the study}

In 1974 the Belgian Ministerial Council approved the National Research Project in the Social Sciences. The objective of this program was to carry out policy preparatory research in four important sectors of social policy: health care, social security, education and social welfare. In Flanders researchers from several universities (Antwerp, Ghent and Leuven) and disciplines (physicians, sociologists and statisticians) decided to cooperate in the Primary Health Care Project.

Two major parts of this project were: health care needs - To determine the needs of the population with regard to health and welfare services, little use could be made of secondary data. Primary data had to be collected via a health interview survey in a sample of the Flemish population (the population study).

A three-fold approach was used to catalogue these needs:

what complaints, disturbances and problems do people have?:

*This study was carried out while the authors had an appointment at the Division of Medical Sociology, Department of Sociology and the Catholic University of Leuven.

†Please address all correspondence to: Marleen Foets, Department of Health Care Administration (SAG), Erasmus University Rotterdam, P.O. Box 1738, 3000 DR Rotterdam, The Netherlands. what health concepts they have, and what are their attitudes with regard to health, illness and the health care supply?;

what behaviour do they display with regard to health and illness?

Health care supply-this part of the study included:

a conceptual clarification of the notion of primary health care;

empirical research into the quantity, density and distribution of primary care services; including their main determinants;

empirical research into the internal structure and functioning of the most significant primary care services (service analysis study);

ideological analysis of how the various services legitimize, through their representative organizations, their involvement in primary care.

Since the very broad study design, an overview will be given of only a selection of interesting results. Attention will be given to the utilization of health care services and of medicines.

\section{Method and sample}

Because of the indicated delimitation of this article, in this section attention will only be paid to the methodology of the health survey interview. Discussed in turn are the research population, the choice of the observation unit, the sampling design and the observation instrument. 
The research population. The research population included all persons who:

reside in the Dutch-language region of Belgium (Flanders). This excludes the French-speaking region, Wallonia and the bilingual region of Brussels, the capital:

are Belgian and Dutch-speaking. Since it is presumed that illness and health behaviour patterns are strongly culture bound, other nationalitits and other linguistic groups are excluded;

are older than 15. This is justifiable on the basis of both interviewing considerations (availability and manner of questioning) and analytical considerations;

are not permanently resident in an institution, such as a prison or a hospital.

Given these limitations, the research population amounts to approximately four million people.

Choice of the obsertation unit. Most 'health surveys' consider the 'household' as the observation unit. Examples are the American 'Health Interview Survey' [1], the English 'General Household Survey' [2] and the French 'Health Survey' [3]. The principal reason for taking the household as the observation unit is the possibility to acquire data on a large number of people by interviewing a small number of respondents. The following disadvantages of this method may be mentioned:

using proxy interviews (i.e. one person reporting on all the other members of the household) is a possible source of underreporting [4];

household surveys create problems in the design of an explanatory model and in the analysis of utilization behaviour. How, for example, is the medical knowledge of the household measured?

For those reasons, the unit of observation in this research project was the individual. Yet there is a difference between the observation unit and the unit of analysis. As will appear from the presentation of the results, the unit of analysis can be as well the individual as the utilization act.

Sampling design. Since the chosen observation unit was the individual, a sample of individuals was selected. It was a two-stage, stratified, cluster sample. In a first stage the municipalities functioned as the primary sample units and were stratified on the basis of urbanization and density of ambulatory health care services. In a second stage, from each of the clusters (municipalities) retained, the necessary constant number of individuals was drawn by simple random sampling. The sample size was limited to 1904 people. The actual number of people included in the final analysis was 1745 because of dropouts, incomplete questionnaires, etc.

Obseriation instrument. A perennial problem in health surveys is the underreporting of the number of health disturbances and acts of medical consumption [5]. Satisfactory resolutions to this problem may be:

the improvement of the interview situation [6] by: conducting multiple interviews

decreasing the recall period in a substantial and/or selective way $[5,7]$;

the addition of a health diary, as e.g. the French Carnet de Santé $[3,4,8,9]$.
Taking into account those considerations. the following observation plan was drawn up for this study:

with a time interval of 3 weeks (the same as used by the French Health Survey) three interviews were conducted, each involving a uniform recall period of 3 weeks:

for the second and third interviews, the respondent was instructed to keep an open-structured health diary for the observation period. The health diary functioned as the starting point for these interviews.

Observation conducted in this way can be considered very satisfactory. The response ratio was $72^{\circ} \ldots$. The minimal dropout rate for the second and third interviews is significant for the evaluation of the feasibility of using health diaries. Indeed. the study showed that the functionality of a health diary consists of its support of the interview: with the health diary at hand, the respondent remembers more events and or more details.

\section{THE UTILIZATION OF HEALTH CARE SERVICES AND OF MEDICINES}

\section{Introduction: the concept of utilization behatiour}

In medical sociology a considerable amount of literature is available that reports on factors explaining why people do or do not use medical services. Utilization behaviour here is generally considered to be the (temporary) end of a process, which usually is called illness behaviour. Illness behaviour has been defined by Mechanic [10] as: "the way in which given symptoms may be differentially perceived, evaluated and acted (or not acted) upon by different kinds of persons". Kasl et al. [11] give a similar definition: "any activity, undertaken by a person who feels ill, to define the state of his health and to discover a suitable remedy". Medical sociologists usually conceive illness behaviour as a 'process' in which the individual passes a number of stages, whereby he has to make choices among different behavioural alternatives. Illness behaviour is a decision-making process. Under the influence of Parsons paradigm of the sick role utilization behaviour, however, is often considered the ideal form of illness behaviour. At the end of the process one has to seek technically competent help, in the most usual case that of a physician [12]. Moreover illness behaviour usually is conccived as a 'social' process. This implies that it is, to a large extent. influenced by a number of personal and social factors. This point will be elaborated into more detail below. Most of the research in this field is concentrated on only one form of illness behaviour, namely utilization behaviour. The use of officially recognized medical services is the core of most studies.

In contrast this study included other forms of illness behaviour. Although the primary focus was on the utilization of health care services, it was expected that other forms of illness behaviour could play a role in the explanation of the use of services. Lay-referral could be mentioned as an example. Its importance in the premedical phase has already been proposed by Freidson [13].

Successively a description and an explanation will bc given of the utilization behaviour of the Flemish 
population. The description includes the hospital stays, but the explanatory part is concentrated on the ambulatory health care services.

\section{Utilization behaviour: a description}

Successively attention will be paid to the use of medical services on the one hand and the use of medicines on the other hand. Both will be described on two levels: on the level of the utilization act, and on the level of the individual.

The use of services: a description on the level of the utilization act. The frequency distribution of the use of medical services is given in Table 1. In total 2925 utilization acts were performed. The general practitioner is very often consulted $(44.9 \%$ of the total acts). Extrapolating on a year-basis, those figures signify a consultation-rate of $4.4 \mathrm{GP}$ contacts per adult per year. Nursing accounts for $17.7 \%$ of the utilization acts; medical specialists for $10.6 \%$. In Belgium no referral is required to consult a specialist. The very low figures for medico-technical examinations $(2.7 \%)$ and for non-official healers $(0.4 \%)$ are presumably to be ascribed to an underreporting effect. This hypothesis is derived from analyses of secondary data, i.e. Belgian social security data for medical-technical examinations and specific studies on the consultation of non-official medicine. The small proportion of obligatory examinations $(2.2 \%)$ screening programs $(1.1 \%)$ and psycho-social services $(0.8 \%)$, in contrast to the high figures for general practitioners, specialists and nurses reveal the curative and somatic accent in Belgian health care. These observations are all the more noteworthy when one realizes that the Belgian curative and somatic health care services are provided by the private sector based on a fee-for-service system. Preventive and social services on the contrary are more often organized as public services, are free for the clients and the care providers are paid on a capitation system-basis.

Theoretically primary health care very often is characterized a non-specialized and easy accessible services. Since there is no official definition of primary health care in Belgium, this care level could be empirically assessed as those services mostly consulted without referral. Looking at Table 2 we may consider the general practitioner as the most clear example of a

Table 1. Frequency distribution of the use of medical services (level of the utilication act

\begin{tabular}{lrr}
\hline Type of consumption & AN & \multicolumn{1}{c}{${ }^{\circ}$} \\
\hline General practitioners & 1314 & 44.9 \\
Popular specialists* & 118 & 4.0 \\
Remaining specialists & 194 & 6.6 \\
\cline { 2 - 3 } & 312 & 10.6 \\
Dentists & 182 & 6.2 \\
Nursing & 518 & 17.7 \\
Physiotherapists & 212 & 7.3 \\
Medico-technical examinations & 78 & 2.7 \\
Obligatory examinations & \\
Screening programs & 64 & 2.2 \\
Hospital stay & 33 & 1.1 \\
Non official hcalcrs & 178 & 6.1 \\
Psycho-social services & 11 & 0.4 \\
\end{tabular}

*This category includes pediatricians. gynecologists, ophthalmologists. dermatologists and otorhinolaryngologists

tConducted within the context of industrial medicine le.g. upon hiring), school medicine. etc.
Table 2. The use of medical services according to referred or patien initiated consumption (level of the utilization act)*

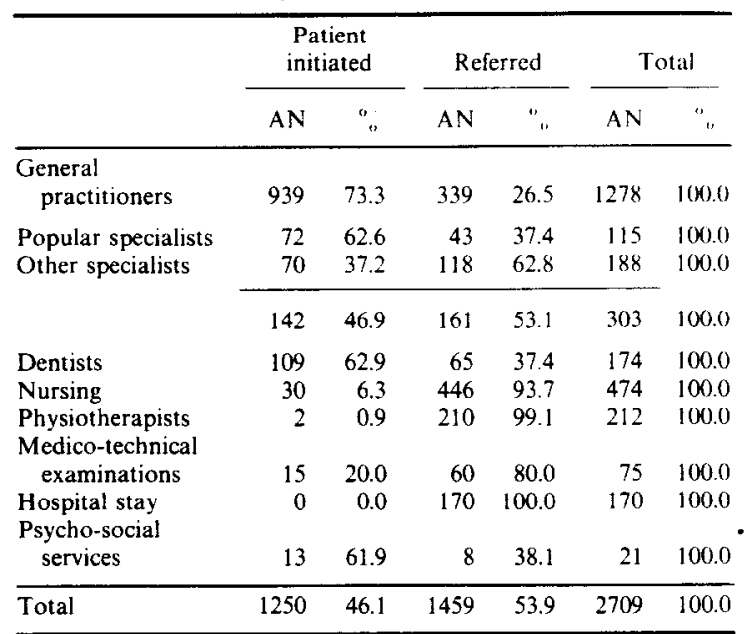

* Differences in numbers compared to Table 1 are due to missing information.

primary health care service, since $73.5 \%$ of their consultations are patient-initiated. They are followed by the popular specialists and the dentists (both $62.6 \%$ ). A combination of the figures in Tables 1 and 2 shows the central position of the general practitioners in Belgian health care. The population clearly considers the general practitioners as the most important entry to the health care system. The higher proportion of patient-initiated use of popular specialists in contrast to the use of other specialists $(62.6 \%$ vs $37.2 \%$ ) confirms the hypothesis that popular specialists are more likely to be primary care providers. The small proportion of patient-initiated consumption of hospital (none: $0.0 \%$ ), physiotherapists $(0.9 \%)$ and nursing $(6.3 \%)$ services also merits further examination. Although the hospital, as other services, is directly accessible, this virtually never occurs. As regards physiotherapists and nursing services, it must be noted that one of the legal conditions for reimbursement by health insurance is the presentation of a referral attest. Thus, the health insurance system does seem to have an effect on the extent of patientinitiated use. In the discussion about the control of health care costs, however, it may be asked whether the low proportion of patient-initiated use of nursing and physical therapy is not offset by a commensurably high proportion of referrals to physiotherapists and nursing services.

The predominance of the curative and somatic components in the Belgian health care system can be illustrated once more by Table 3. Classified according to the reasons for utilization behaviour $70.1 \%$ of the total use occurred as a result of health complaints Moreover $17.9 \%$ was recorded as check-up consultations, what indicates the presence of latent health complaints. Only $4.5 \%$ of the total use was described as occurring for precentive reasons. The relatively low proportion of complaint-bonded use of $\left(42.4^{\circ}\right)$ population screening is still surprisingly high since, by definition, population screening is precentive care. With $11.7 \%$ of the dental consultations being preventive, dental services is, after screening, the most often consulted for preventive reasons. 
Table 3. The use of medical services according to the reasons for consumption. (level of the utilization act)*

\begin{tabular}{|c|c|c|c|c|c|c|c|c|c|c|c|c|}
\hline \multirow[b]{2}{*}{ Reason for consumption } & \multicolumn{2}{|c|}{$\begin{array}{l}\text { Health } \\
\text { complaints }\end{array}$} & \multicolumn{2}{|c|}{ Prevention } & \multicolumn{2}{|c|}{$\begin{array}{l}\text { Check-up } \\
\text { consultation }\end{array}$} & \multicolumn{2}{|c|}{ Certificates } & \multicolumn{2}{|c|}{ Other } & \multicolumn{2}{|c|}{ Total } \\
\hline & $A N$ & $\%$ & AN & $\%$ & AN & $\because$ & AN & ${ }_{0}^{\circ}$ & $A N$ & $" n$ & $\mathrm{AN}$ & $" "$ \\
\hline General practitioners & 926 & 70.8 & 47 & 3.6 & 283 & 21.6 & 27 & 2.1 & 25 & 1.9 & 1.308 & 100,0 \\
\hline Popular spucialists & 63 & 54.8 & 4 & 3.5 & 45 & 39.1 & 0 & 0.0 & 3 & 2.6 & 115 & 100.0 \\
\hline \multirow[t]{2}{*}{ Other specialists } & 159 & 82.4 & 7 & 3.6 & 25 & 13.0 & 0 & 0.0 & 2 & 1.0 & 193 & 100.0 \\
\hline & 222 & 72.1 & 11 & 3.6 & 70 & 22.7 & 0 & 0.0 & 5 & 1.6 & 308 & 100.0 \\
\hline Dentists & 122 & 67.8 & 21 & 11.7 & 22 & 12.2 & 1 & 0.6 & 14 & 7.8 & 180 & 100,0 \\
\hline Nursing & 343 & 66.2 & 30 & 5.8 & 67 & 12.9 & 0 & 0.0 & 78 & 15.1 & 518 & 100.0 \\
\hline Physiotherapists & 163 & 76.9 & 2 & 0.9 & 4 & 1.9 & 0 & 0.0 & 43 & 20.3 & 212 & 100.0 \\
\hline $\begin{array}{l}\text { Medico-technical } \\
\text { examinations }\end{array}$ & 59 & 75.6 & 1 & 1.3 & 17 & 21.8 & 1 & 1.3 & 0 & 0.0 & 78 & 100.0 \\
\hline Obligatory examinations & 3 & 4.8 & 0 & 0.0 & 56 & 90.3 & 3 & 4.8 & 0 & 0.0 & 62 & 100.0 \\
\hline Screening programs & 14 & 42.4 & 19 & 57.6 & 0 & 0.0 & 0 & 0.0 & 0 & 0.0 & 33 & 100.0 \\
\hline Hospital stay & 169 & 94.9 & 0 & 0.0 & 0 & 0.0 & 0 & 0.0 & 9 & 5.1 & 178 & 100.0 \\
\hline Non official healers & 11 & 100.0 & 0 & 0.0 & 0 & 0.0 & 0 & 0.0 & 0 & 0.0 & 11 & 100.0 \\
\hline Psycho-social services & 8 & 34.8 & 0 & 0.0 & 2 & 0.0 & 0 & 0.0 & 13 & 56.5 & 23 & 100.0 \\
\hline Total & 2040 & 70.1 & 131 & 4.5 & 512 & 17.9 & 32 & 1.1 & 187 & 6.4 & 2911 & 100.0 \\
\hline
\end{tabular}

*Same remark as in Table 2.

$A$ description on the level of the individual. The distribution of the consumption over the research population by consumption category provides a number of supplementary data for the description on the level of the act. $50.1 \%$ of the total research population $(N=1745)$ consulted at least one of the services during the nine-week observation period (c.f. Table 4). Of them, more than half consulted a service more than once. These figures show how much health and health care are an essential and integral element in the life style of the population. Once again it becomes clear how central the position of general practitioners is : $36.1 \%$ of the research population consulted him or her at least once during the period of observation. Nearly half of them consulted him or her more than once. All the other services are consulted by less than $10 \%$ of the research population. Screening programs, non-official healers and psychosocial services obtain very low figures (less than $1 \%$ of the population). This again demonstrates the marginal character of preventive, psychosocial and non-official services. Finally, the distribution of the use of nursing services over a narrow segment of the population $(2.1 \%)$ is striking, since this use comprises a considerable proportion of the total utilization acts (cf. Table 1). Probably this is due to the fact that the nursing services are mostly used by chronically ill and elderly persons: a relative small group of the population, yet frequently appealing to those services.

The use of medicines. Two elements have to be clarified at the outset, namely the measurement unit used and the pharmaceutical classification applied. Because of the various packaging units on the market. measurement of medication in terms of number of packages used' is rather difficult. Moreover, measurement in terms of 'number of packages used' is inadequate to determine partial use of purchased medications. Therefore, the number of use days per medication (the day dose) was chosen as the measurement unit. The pharmaceutical classification employed is a classification system developed by the physicians members of the research teams. The starting points for the construction of this classification were, on the one hand, their own pharmaceutical knowledge, and, on the other, an overview of the observed pharmaceuticals. Table 5

Table 4. Frequency distribution of the use of medical services (level of the individual)

\begin{tabular}{|c|c|c|c|c|c|c|c|c|}
\hline \multirow[b]{2}{*}{ Frequency of use } & \multicolumn{2}{|c|}{ Never } & \multicolumn{2}{|c|}{ Once } & \multicolumn{2}{|c|}{ More than once } & \multicolumn{2}{|c|}{ Total } \\
\hline & $\mathbf{A N}$ & $\%$ & $A N$ & $\%$ & $A N$ & $\%$ & AN & $\%$ \\
\hline General practitioners & 1115 & 63.9 & 337 & 19.3 & 293 & 16.8 & 1745 & 100.0 \\
\hline Popular specialists & 1653 & 94.7 & 72 & 4.1 & 20 & 1.2 & 1745 & 100.0 \\
\hline Other specialists & 1658 & 95.0 & 46 & 2.6 & 41 & 2.4 & 1745 & 100.0 \\
\hline Dentists & 1635 & 93.7 & 75 & 4.3 & 35 & 2.0 & 1745 & 100.0 \\
\hline Nursing & 1709 & 97.9 & 23 & 1.3 & 13 & 0.8 & 1745 & 100.0 \\
\hline Physiotherapists & 1723 & 98.7 & 4 & 0.2 & 18 & 1.6 & 1745 & 100.0 \\
\hline Medico-technical & & & & & & & & \\
\hline examinations & 1680 & 96.3 & 54 & 3.1 & 1.1 & 0.6 & 1745 & 100.0 \\
\hline Obligatory examinations & 1656 & 94.9 & 78 & 4.5 & 11 & 0.7 & 1745 & 100.0 \\
\hline Screening programs & 1734 & 99.4 & 11 & 0.6 & 0 & 0.0 & 1745 & 100.0 \\
\hline Hospital stay & 1714 & 98.2 & 31 & 1.8 & 0 & 0.0 & 1745 & 100.0 \\
\hline Non official healers & 1733 & 99.3 & 10 & 0.6 & 2 & 0.1 & 1745 & 100.0 \\
\hline Psycho-social services & 1733 & 99.3 & 8 & 0.5 & 4 & 0.3 & 1745 & 100.0 \\
\hline Total & 870 & 49.9 & 386 & 22.1 & 489 & 28.0 & 1745 & 100.0 \\
\hline
\end{tabular}


Table 5. Overview of the drug categories

\begin{tabular}{|c|c|c|}
\hline Codename & Category & Clarification \\
\hline Analgesics & Analgesics & Drugs against pain, fever and inflammation \\
\hline Cough & Cough remedies & Drugs against cough and/or for expectoration \\
\hline Cold & Common cold remedies & $\begin{array}{l}\text { Other than above also eye and nose drops and } \\
\text { mouthwaters }\end{array}$ \\
\hline Ointments & Ointments and antiseptics for the skin & \\
\hline Revuls & Revulsive ointments and solutions & External treatment for painful and stiff muscles \\
\hline Stools & Purges and antidiarrheal agents & \\
\hline Stomach & $\begin{array}{l}\text { Agents against all kind of } \\
\text { stomach diseases }\end{array}$ & Also bile-diseases \\
\hline Sleep & Hypnotics & \\
\hline Vitamins & Vitamins and tonics & Also enzyms, oligo-elements and 'liver remedies' \\
\hline Sedatives & Sedatives & All non-hypnotic tranquillizers \\
\hline Allergy & Anti-allergics & Drugs used in allergic disorders \\
\hline Antibiotics & $\begin{array}{l}\text { Antibiotics, sulfonamides and } \\
\text { antimycotics }\end{array}$ & Antimycotics - against fungi \\
\hline Hormones & Hormones & Exept. corticosteroids \\
\hline Cortico & Corticosteroids & $\begin{array}{l}\text { Also ACTH } \\
\text { Exept. corticosteroids in ointments and solutions }\end{array}$ \\
\hline Vasodilators & Vasodilators & Effectiveness of these drugs is not proven \\
\hline Heart & $\begin{array}{l}\text { Other drugs against cardiovascular } \\
\text { diseases }\end{array}$ & $\begin{array}{l}\text { Effective drugs against heart and great vessels } \\
\text { disorders }\end{array}$ \\
\hline Diuretics & Diuretics & Removal of water from the body \\
\hline Hypertension & Hypotensive drugs & \\
\hline Bronchodilators & Bronchodilators & \\
\hline Psycho. & Psychofarmaca & Other than sedatives or hypnotics \\
\hline Spasma & Spasmolytics & Agents against cramps of bowel, kidney, etc. \\
\hline Specific & Other specific therapy & Specific drugs against disorder as diabetes, etc. \\
\hline Magistral & Compound prescriptions & Unless related to one of the other categories \\
\hline Homeopatics & Homeopatics & Also 'natural' products \\
\hline Antimit. & Antimitotica & Cancer treatment \\
\hline Vaccine & Vaccines & Vaccinations against several diseases \\
\hline Not classif. & Not to classify & \\
\hline
\end{tabular}

gives the code names for each classification category, which names are used in the remaining tables, and description and further clarifications of the categories.

A description on the level of the utilization act. Table 6 gives the frequency distribution of the use of medicines. In total 60,722 day doses of medicines were consumed. This implies that each member of the research population uses one day dose every 2 days. The threshold for the use of medicines thus seems to be very low. Cardiovascular medication forms the largest category $(10.4 \%)$. Together with the diuretics, the antihypertensives and vasodilators, this category represents almost $25 \%$ of the total use of medicines. The quantitative importance of this category is to be ascribed to the chronical use of such drugs, since in approx. $80 \%$ of the cases they are used during more than 3 weeks of the observation period. The latter is not true for analgesics, which nevertheless constitutes the second important category $(8.8 \%)$. Most of them, also approx. $30 \%$, are used at most during one week. Those figures are presumably related to the self-perception of the respondents with regard to their health status. Indeed the research results showed that $64.6 \%$ of the population formulated at least one health complaint, whereby complaints of pain were particularly common. Sedatives and tranquilizers occupied the third place with $7.5 \%$, which confirms the well-known hypothesis regarding the extent of the use of such forms of medication. Vitamins and antibiotics also occupy a rather important portion of the medications used. In the discussion regarding 'over and/or under-consumption' of medicines, the argument of self-medication is often introduced. It is suggested that the population regularly uses too much medication on its own initiative and thus is itself responsible for the possible damage results. Table 7 provides the necessary information in this context. $85.6 \%$ of the total use of day doses was prescribed by a physician. A very small proportion 
Table 6. Frequency distribution of the use of medicine (level of the utilization act)

\begin{tabular}{lcc}
\hline \multicolumn{1}{c}{ Category } & $\begin{array}{c}\text { Number of day } \\
\text { doses }\end{array}$ & \multicolumn{1}{c}{$\%$} \\
\hline Heart & 6344 & 10.4 \\
Analgesics & 5325 & 8.8 \\
Sedatives & 4575 & 7.5 \\
Vitamins & 3612 & 5.9 \\
Antibiotics & 3596 & 5.9 \\
Vasodilators & 3428 & 5.6 \\
Diuretics & 3098 & 5.1 \\
Ointments & 2911 & 4.8 \\
Psycho. & 2635 & 4.3 \\
Cough & 2325 & 3.8 \\
Hypertension & 2193 & 3.6 \\
Stomach & 1977 & 3.3 \\
Magistral & 1820 & 3.0 \\
Sleep & 1789 & 2.9 \\
Cold & 1688 & 2.8 \\
Hormones & 1406 & 2.3 \\
Stools & 1071 & 1.8 \\
Homeopathics & 1044 & 1.7 \\
Bronchodilators & 1031 & 1.7 \\
Allergy & 953 & 1.6 \\
Cortico & 749 & 1.2 \\
Revuls. & 559 & 0.9 \\
Spasmo. & 408 & 0.7 \\
Specific & 3448 & 5.7 \\
Not classif. & 2725 & 4.5 \\
\hline Total & 60,722 & 100.0 \\
\hline
\end{tabular}

$(1.8 \%)$ was used on the advice of a pharmacist, and the amount of self-medication comprised barely $12.6 \%$. This low figure is an initial qualification of the attention given to self-medication in the discussions on the matter. Moreover, Table 7 shows that self-medication is also a selective phenomenon: self-medication occurs clearly with respect to a restricted number of pharmaceutical categories. More than $30 \%$ of the use of

Table 7. Use of medicines according to prescribed or non-prescribed use (level of the utilization act)

\begin{tabular}{|c|c|c|c|c|c|}
\hline \multirow[b]{2}{*}{ Category } & \multicolumn{2}{|c|}{$\begin{array}{l}\text { Prescribed } \\
\text { by physician }\end{array}$} & \multicolumn{2}{|c|}{$\begin{array}{c}\text { Not } \\
\text { prescribed }\end{array}$} & \multirow[b]{2}{*}{ Total } \\
\hline & AN & 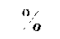 & $A N$ & $\%$ & \\
\hline Homeopathics & 486 & 48.0 & 526 & 52.0 & 1012 \\
\hline Cold & 838 & 51.1 & 802 & 48.9 & 1640 \\
\hline Analgesics & 3069 & 59.0 & 2139 & 41.0 & 5208 \\
\hline Revuls. & 332 & 60.5 & 217 & 39.5 & 549 \\
\hline Cough & 1580 & 69.3 & 700 & 30.7 & 2280 \\
\hline Stomach & 1480 & 76.0 & 468 & 24.0 & 1948 \\
\hline Ointments & 2139 & 76.9 & 642 & 23.1 & 2781 \\
\hline Stools & 886 & 83.5 & 175 & 16.5 & 1061 \\
\hline Sleep & 1497 & 85.7 & 249 & 14.3 & 1746 \\
\hline Allergy & 800 & 86.2 & 128 & 13.8 & 928 \\
\hline Sedatives & 3886 & 86.4 & 612 & 13.6 & 4498 \\
\hline Vitamins & 3072 & 86.7 & 474 & 13.3 & 3546 \\
\hline Magistral & 1655 & 90.4 & 156 & 8.6 & 1811 \\
\hline Hormones & 1300 & 93.9 & 84 & 6.1 & 1384 \\
\hline Diuretics & 2810 & 93.9 & 183 & 6.1 & 2993 \\
\hline Antibiotics & 3296 & 94.9 & 180 & 5.1 & 3476 \\
\hline Cortico. & 712 & 95.1 & 37 & 4.9 & 749 \\
\hline Bronchodilators & 991 & 96.2 & 39 & 3.8 & 1030 \\
\hline Heart & 6096 & 97.4 & 163 & 2.6 & 6250 \\
\hline Spasmo. & 371 & 97.9 & 8 & 2.1 & 379 \\
\hline Vasodilators & 3351 & 98.6 & 48 & 1.4 & 3399 \\
\hline Hypertension & 2117 & 99.0 & 21 & 1.0 & 2138 \\
\hline Psycho. & 2611 & 99.3 & 19 & 0.7 & 2630 \\
\hline Not classif. & 2283 & 84.7 & 412 & 15.3 & 2695 \\
\hline Specific & 3255 & 96.1 & 128 & 3.9 & 3383 \\
\hline Total & 50,913 & 85.6 & 8610 & 14.4 & 59,523 \\
\hline
\end{tabular}

homeopathic medications, cold and cough medications, analgesics and revulsive salves are selfmedication. Characteristics of these categories is that they concern primarily medically unimportant acute complaints such as a common cold or a flu.

$A$ description on the level of the inditidual. On the average, each member of the research population used 1 day dose per 2 days, as stated in Table 8. Table 9. however, provides some more empirical refinement. The total number of medicine takers in the population comprised only $63 \%$. This implies two things: first. that $37 \%$ of the population succeeds in living without medicines, and second, that the $63 \%$ of the medicine takers use many drugs. Finally, Table 9 gives the distribution of medicine use per category on the level of the individual. Analgesics, revulsive salves, antibiotics. sedatives and cold medications are distributed over more than $10 \%$ of the population. Analgesics clearly comprise the largest category $(33.2 \%)$. The hypothesis that the high use of cardiovascular medicines is to be explained by habitual use is confirmed by this table: this category included only $7.6^{\circ}$ of the population.

Table 8. Total use of medicines according to duration (level of the individual )

\begin{tabular}{lrr}
\hline \multicolumn{1}{c}{ Duration } & AN & \multicolumn{1}{c}{$"$} \\
\hline 1-2 days & 162 & 9.3 \\
3 days -1 week (7 days) & 175 & 10.0 \\
I week (8 days)-2 weeks (14 days) & 142 & 8.1 \\
2 weeks (15 days)-3 weeks (21 days) & 107 & 6.1 \\
$>3$ weeks & 514 & 29.4 \\
\hline Total number of consumers & 1100 & 63.0 \\
\hline Total number of non-consumers & 645 & 37.0 \\
\hline Total number of respondents & 1745 & 100.0 \\
\hline
\end{tabular}

Table $y$. Use of medicines according to prescribed or non-prescribed use (level of the individual)

\begin{tabular}{|c|c|c|c|c|c|c|}
\hline \multirow[b]{2}{*}{ Category } & \multicolumn{2}{|c|}{$\begin{array}{c}\text { Prescribed } \\
\text { by physician }\end{array}$} & \multicolumn{2}{|c|}{$\begin{array}{c}\text { Not } \\
\text { prescribed }\end{array}$} & \multicolumn{2}{|c|}{ Total } \\
\hline & AN & 0 & $\mathrm{AN}$ & $\because$ & AN & ${ }_{0}$ \\
\hline Analgesics & 166 & 9.5 & 479 & 28.4 & 579 & 33.2 \\
\hline Ointments & 109 & 6.2 & 102 & 5.8 & 194 & 11.1 \\
\hline Antibiotics & 166 & 9.5 & 30 & 1.7 & 191 & 10.9 \\
\hline Sedatives & 139 & 8.0 & 68 & 3.9 & 187 & 10.7 \\
\hline Cold & 57 & 3.3 & 138 & 7.9 & 181 & 10.4 \\
\hline Vitamines & 123 & 7.0 & 46 & 2.6 & 168 & 9.1 \\
\hline Cough & 83 & 4.8 & 70 & 4.0 & 143 & 8.2 \\
\hline Heart & 124 & 7.1 & 19 & 1.1 & 132 & 7.6 \\
\hline Stomach & 64 & 3.7 & 77 & 4.4 & 130 & 7.4 \\
\hline Vasodilators & 77 & 4.4 & 7 & 0.4 & 82 & 4.7 \\
\hline Diuretics & 76 & 4.4 & 11 & 0.6 & 80 & 4.6 \\
\hline Magistral & 71 & 4.1 & 13 & 0.7 & 80 & 4.6 \\
\hline Stools & 38 & 2.2 & 39 & 2.2 & 75 & 4.3 \\
\hline Sleep & 45 & 2.6 & 22 & 1.3 & 62 & 3.6 \\
\hline Revuls. & 18 & 1.0 & 45 & 2.6 & 60 & 3.4 \\
\hline Psycho. & 51 & 2.9 & 11 & 0.6 & 59 & 3.4 \\
\hline Homeopathics & 16 & 0.9 & 43 & 2.5 & 58 & 3.3 \\
\hline Hypertension & 57 & 3.3 & 7 & 0.4 & 57 & 3.3 \\
\hline Hormones & 39 & 2.2 & 5 & 0.3 & 41 & 2.3 \\
\hline Allergy & 30 & 1.7 & 9 & 0.5 & 36 & 2.1 \\
\hline Spasmo & 24 & 1.4 & 5 & 0.3 & 28 & 1.6 \\
\hline Bronchodilators & 23 & 1.3 & 3 & 0.2 & 26 & 1.5 \\
\hline Cortico. & 24 & 1.4 & 4 & 0.2 & 26 & 1.5 \\
\hline Vaccine & 7 & 0.4 & 11 & 0.6 & 18 & 1.0 \\
\hline Ointments & 4 & 0.2 & 6 & 0.3 & 10 & 0.6 \\
\hline Antimit. & 2 & 0.1 & -.- & $\ldots$ & 2 & 0.1 \\
\hline Specific & 84 & 4.8 & 24 & 1.4 & 102 & 5.8 \\
\hline Not classif. & 105 & 6.0 & 62 & 3.6 & 162 & 9.3 \\
\hline
\end{tabular}




\section{Utilization behation: an explanation}

Introduction. In their attempts to find an explanation for utilization behaviour, behavioural scientists have developed a number of explanatory models. Most of these models, however, suffer from the same flaw: one or another form of onesideness.

(1) Some models relate utilization behaviour and other forms of illness or health behaviour univocally to specific kinds of variables, for example, demographic, socio-psychological, socio-cultural or economic variables. Because most of these models overlook the complexity of social reality, their value is more descriptive than explanatory.

(2) Another form of onesideness often encountered in those explanatory schemes is restriction to individual, person-bonded factors. Social factors are generally also mentioned, but without their specific influence on medical consumption being investigated. The influence, for example, of the organization of the medical supply on illness behaviour and medical consumption is largely ignored

The Primary Health Care Research Project has attempted to surmount these limitations in its explanation of utilization behaviour. In the construction of its own explanatory model for the purposes of the populaton study, the WHO model functioned as an important source of inspiration. Indeed. the explanatory factors used in the WHO model include a number of system variables as well as 3 types of variables on the level of the individual: perceived morbidity, predisposing factors and enabling factors [7].

Perceited morbidity. Both in the WHO model and in our explanatory schema, the perceived morbidity or the complaint is seen as the force which initiates decision making in the process of illness behaviour. The underlying hypothesis is that it is people's beliefs about their health, rather than clinicially objective states, that are the major determinants of illness behaviour in general and the non-referred utilization behaviour particularly. In order to obtain information on this perceived morbidity the respondents were asked to report their current problems and complaints during the 9 weeks observation period.

Predisposing and enabling factors. Once people have reasons by virtue of their perceived morbidity for seeking care. the decision is further influenced on the individual level by socio-cultural factors that predispose or deter from the use of formal health services (predisposing factors), and by the cost of pursuing that coursc of action (cnabling factors). In our own explanatory scheme. this implies a number of both individual characteristics and characteristics of the household of which the individual is a part. A central place in the model is occupied by a set of knowledge and attitude variables. which are combined under the concept of "health perspective".

Sistems factors. An important advantage of the WHO model and our own explanatory schema is the attention given to a series of institutional factors. These variables, which are ignored in most studies. characterize the context in which the individual decision making process occurs. Unlike the perceived morbidity and the socin-cultural factors, which are variables that are attributes of individuals, systems factors are constant for all people within a particular population. Systems factors not only include such variables as degree of urbanization, but also data on the quantity and the quality of the health services available.

The explanatory schema used in the Primary Health Care Research Project thus consists of an extended series of hypothetically influencing factors:

structural background characteristics of the individual and of the individual's household;

the past and current morbidity profile of the individual and of the members of the household:

the past experience of the individual with health care services;

the health perspective of the individual

the illness behaviour developed by the individual on the basis of perceived morbidity;

the presence and actual operation of the medical supply;

the socio-structural context of the individual

In the descriptive section the heterogeneous character of utilization behaviour has already been illustrated, as well as the quantitative differences in the occurrence of the various forms of use of services. The further exposition will therefore be limited to a number of quantitatively sufficiently large forms of utilization behaviour. Thus attention will be paid to general practitioners, specialists, global medication and selfmedication. This explanatory schema of utilization behaviour is obviously very complex. It will be clear to the reader that complete testing of this schema requires very advanced procedures of multivariable analysis. Moreover, the controlling possibilities are limited by the size of the sample and the broad definition of the test population. No doubt, future research will have to concentrate on specific hypotheses and on specific populations such as young people or the chronically ill. The results given below, consequently, are of an exploratory nature and, perhaps, can give rise to more well-founded hypotheses, which may be tested by further research. The analysis has been carried out by means of factorial experiment, in which the dependent variable is expressed as a mean per unit of analysis. The variables 'urbanization', 'sex' and 'age' have always been held under control.

The influence of perceived morbidity and disability on utilization behaviour

Perceived presence of morbidity. Already more than once the predominantly curative character of Belgian care has been stressed. Therefore, one may expect that the perceived morbidity as indicated by the formulation of complaints, will be a necessary condition for medical consumption. The research results indeed show a strong relationship between the presence or absence of health complaints and utilization behaviour. The people with health complaints account for $90.6 \%$ of the total use of general practitioners, $91.4 \%$ of the specialists, $84 \%$ of the global use of medicines and $93.5 \%$ of the self-medication. On the basis of this observation, it was decided to keep the complaint variable under control for all of the further 
analysis in order to exclude its possible intervening influence between the other explanatory variables and utilization behaviour. This means limiting the population to people with health complaints, which yielded a total number of 1.127 units. Although the manifestation of complaints was a necessary condition for medical consumption, it was not a sufficient condition: from the descriptive results, it appeared that $23.7 \%$ of the complaints were not followed by any form of utilization behaviour, and there was still a portion of use of services that was not based on complaints.

Perceived seriousness of morbidity. The statement on the influence of perceived morbidity on utilization behaviour can be further refined: the more serious the complaint, the greater the chance of utilization behaviour. Because the present study is a health interview study, the degree of seriousness was not indicated by means of medical criteria. Rather, seriousness is here indicated by:

the average duration of the complaint;

the inability to carry out activities essential to daily living;

the development of several forms of illness behaviour.

A longer average duration of the complaints is clearly associated with more utilization (general practitioner services and medicines).

The so-called 'Activities of Daily Living' (ADL) and 'Sickness Impact Profile' (SIP) are sufficiently wellknown as attempts to measure the behavioural limitations of illness. The application of a very limited measurement instrument on the level of ADL in this study shows a clear relationship between the manifestation of behavioural impact and utilization behaviour. In the present study illness bchaviour is operationalized by: complete or partial disruption of daily activities, confinement to bed and lay referral. Over the entire range, a clear relationship appears: the development of illness behaviour is clearly associated with more utilization behaviour.

The influence of socio-cultural factors on utilization behaviour. Several research results [14] point to the importance of socio-cultural factors in the explanation of illness behaviour. In the delineation of the conceptual framework, the central role of the health perspective in the explanation of utilization behaviour already has been indicated. In the present study an attempt was made to operationalize these determinants by distinguishing different dimensions within the global concept of health perspective. For each of those dimensions one or more scales were constructed. The most important aspects of the health perspective, included in this research project are:

Medical knowledge, including both the knowledge of illness and health problems, and the knowledge of the existence and the functioning of health care services.

The basic concepts of health and illness, which may be ration-scientific or irrational, compared to the concepts currently present by the health care providers.

The evaluation of different services (general practitioners, specialists, etc.).
The feeling of powerlessness. both in the area of illness and health, and in other areas of life.

On the basis of the research results two hypotheses can be formulated. which. in any event. must be tested by further research.

(1) The health perspective is not of decisive significance for the volume of the medical consumption. But it does play an important role in the choice that is made between utilization alternatives.

(2) Differences in age and social background are associated with different health perspectives. which in turn lead to different patterns of utilization behaviour. Thus the health perspective intervenes in the relationship between age and social background, and utilization behaviour.

Hypothesis $I$. The most striking relationship between health perspective and utilization behaviour can be stated as follows:

More feelings of powerlessness in general and towards health, lead to more appeals to general practitioners, specialist services and to more use of medicines.

More rational concepts of illness, expressed in a lack of faith in methods of natural healing and in the absence of moral and religious concepts of illness, lead to more use of specialist and general practitioner services. On the other hand more irrational concepts increase the use of medicines. A high degree of medical knowledge leads to more use of specialist services; it seems to have little or no influence on the use of general practice service. Nor is there a univocal conclusion possible with respect to the relationships between medical knowledge and the use of medicines. The influence of medical knowledge in this regard seems not only to act differently in various groups of respondents, but also to be different for the various pharmaceutical categories.

Hypothesis $I I$. In relating the variables of age and social level to the health perspective variables and the various consumption categories, the major types of consumers appear. On the one hand are the respondents with a rather magical-traditional approach to illness and health, who often call upon the general practitioner and take a considerable amount of medication. One encounters them mostly among the elderly and on the lower social levels. On the other hand are the respondents with more modern, scientific conceptions, who turn less to the general practitioner, are more critical on the use of medicine, but are the largest consumers of specialist services. One meets them among the younger people and on the higher social level.

A magical-traditional approach to illness and health is characterized by less medical knowledge, more irrational concepts of illness and strong anomic feelings. The relationship between age and social level on the one hand, and the various consumption categories on the other, were indeed confirmed in the present study. Elderly people and people from lower social levels do have a greater degree of utilization of the general practitioner services and a greater use of medicine. Younger people and people from higher social levels manifest a higher degree of consumption 
of specialist services. The question is now whether the health perspective intervenes, and, if yes, in what sense.

The relationships uncovered suggest the following:

A higher age and a lower social level do lead to more feelings of powerlessness, more irrational concepts of illness and less knowledge of medicine, factors that each in their turn augment the utilization of general practitioner services as well as that of medications. A younger age and a higher social level, on the contrary, lead to more rational concepts of illness and a high degree of medical knowledge, factors that in their turn positively influence the utilization of specialist services This group is also characterized by a more critical approach to the medical supply, which can account for the lesser degree to which they use medicines.

Accessibility and utilization behaviour. In addition to perceived morbidity and the health perspective, the utilization of general practitioners, specialist services and medicines, is also determined by a number of factors that can be combined under the common denominator of accessibility. Accessibility refers in the first place to psychological thresholds. Differen factors, included in the explanatory scheme, fulfill a socialization function to the entire health care system. In other words, they have a threshold lowering effect with respect to the consultation of physicians and the used medicines. Past experiences with serious illness and experience with chronic diseases are factors increasing the different forms of utilization behaviour. The treatment of those conditions undoubtedly include a more or less intensive contact with the medical supply. These contacts probably lower the threshold for utilization behaviour with respect to actual health complaints. This socialization hypothesis is indeed further supported by the positive relationship between the consultation of general practitioners and the use of medicines on the one hand, and the past use of a number of medical services on the other. The same decreased social distance is also seen when there are elderly people and/or children in the household: through their utilization behaviour, one becomes more familiar with the medical supply upon which the social distance decreases and the consultations of general practitioners as well as the use of medicine consequently increases.

Financial accessibility also plays a role. Employees, a category with complex coverage by the health insurance, call more upon the general practitioner and the specialist than do the self-employed who are not insured against 'minor' risks. In the same perspective, one can explain the observation that the self-employed manifest a higher degree of self-medication and a longer period of global medication than do those with complete coverage.

Further, accessibility may be associated with the manner in which the medical supply is evaluated. Thus, a positive evaluation of the general practitioner leads to more consultations of general practitioner services and a higher use of medicines. Also, negative evaluations of specialist services go together with more consultations of general practitioners. The observation that the elderly and people from lower social levels evaluate the general practitioner positively and the specialist negatively and also are the largest consumers of general practitioner services and medications illustrates the intermediating effect of this satisfaction threshold.
The influence of socio-structural factors on utilization behaviour. Because individual behaviour cannot be explained only by individual characteristics, our explanatory scheme also includes a number of factors characterizing the broader social context to which the respondent belongs. Both, socio-structural variables and the proximity and the way of functioning of the medical supply are taken up in the explanatory scheme.

A high degree of urbanization of the community in which the respondent lives seems to have a positive effect on the consultation of specialist services. The relationships are unclear with regard to the consultation of general practitioners and the use of medicines.

Previous studies have revealed few connections between medical supply and utilization behaviour. The present study, therefore, provides new information on this regard. In contrast to what is generally expected, a greater density of physicians does not lead to more consultation of physicians. A greater concentration of general physicians-on the other hand-decreases the utilization of general practice services, and a greater concentration of specialists decrease the utilization of specialist services. This may indicate that there is a critical threshold above which a higher supply does not result in more utilization behaviour. Moreover it suggests the existence of a market regulating mechanism, already mentioned in other research [15].

There is also a noteworthy connection between a low availability (indicated by a little amount of time available for the patient) of general practitioners and a greater use of general practitioner services. Formulated positively, a greater accessibility of the general practitioner, indicated by a more patientoriented organization of his practice, can depress the use of general practitioner services.

\section{CONCLUSION}

The explanation of utilization behaviour is approached theoretically as a complex phenomenon. Therefore, a very broad explanatory schema was sketched. So far, the research results have successfully shown that:

There is a clear and strong relationship between the perceived presence and perceived seriousness of morbidity on the one hand and utilization behaviour on the other.

The health perspective seems to have a differential influence on utilization behaviour depending on age and social background of the respondent.

The factors of accessibility and socialization have a very clear influence on the use of general practitioner services, and partly confirm the importance of the supply of the explanation of utilization behaviour.

The inclusion of a number of socio-structural variables is an innovation for this field of research. The hypothetical character of the relationships found here is largely supported by the research conducted simultaneously in the French-speaking region of Belgium [15]

Any explanatory schema that does not take account of the influence of all these variables threatens to 
oversimplify the complexity of the phenomena of illness and utilization behaviour. Nevertheless, we must stress the temporary and exploratory character of this study. A large number of the relationships discovered undoubtedly need further testing and are, in this sense, subject to refinement and correction.

Acknowledgements-The authors wish to thank Professor Y. Nuyens and Professor J. Vanhoutvinck, under whose supervision this study has been carried out. Also they are obliged to their former colleagues, of whom especially Mark Van Riet and Jan van Tricht have been central persons in the health interview study. Finally we thank Els van der Schee and Chantal Koudenburg for their typing of the manuscript.

\section{REFERENCES}

1. NCHS. Health Interview Survey Procedure 1957-1974, Vital and Health Statistics, Series 1, No. 11, 1975.

2. Office of Population Censuses and Surveys. Social survey division. The General Household Survey. HMSO, London, 1973.

3. INSEE. Les Consommations Médicales des Français. Série M, No. 57, 1977 .

4. Roghman K. and Haggerty R. J. The diary as a research instrument in the study of health and illness behaviour. Med. Care 10, 143-163, 1972. Feldman J, J. The household interview survey as a technique for the collection of morbidity data. J. chron. Dis. 11, 535-557, 1960.
5. Mechanic D. Medical Sociology: A Selectue View. The Free Press, New York, 1968

6. Canell C. F., Oksemberg L. and Converse J. M. Experiments in Interviewing Techniques. University of Michigan, Michigan. 1979.

7. Kohn R. and White K. L. (Eds) Health Care. An International Study. Oxford University Press, London. 1976.

8. Banks H. M. Factors influencing demand for primary medical care in women aged 20-44 years. Int. J. Epid. 189. 1975 .

9. NCHS. Reporting health events in household interviews: effect of and extensive questionnaire and a diary procedure. Vital and Health Statistics, Series 2, No. 49. 1972.

10. Mechanic D. and Volkart E. Stress, illness behaviour and the sick role. J. chron. Dis. 1, 51-58, 1960.

11. KaslS. V. and CobbS. Heaith behaviour, illness behaviour and sick role behaviour. Archs encir. Hith 12, 246-267. 1966.

12. Parsons T. The Social System. Routledge \& Kegan Paul, London, 1951.

13. Freidson E. Profession of Medicine. A Study of the Sociology of Applied Knowledge, pp. 278-301. Dodd. Mead, New York, 1973.

14. McKinlay J. B. Some approaches and problems in the study of the use of services -an overview. J. Hith soc. Behav. 13, 115-152, 1972.

15. Programme National de Recherches en Sciences Sociales. Offre et consommation de soins en médicine générale. Analyse régionale; mecanismes du marché: indicateurs de besoins. Rapport No. 2, Programmation de la Politique Scientifique, Bruxelles, 1978. 